Network Working Group

Request for Comments: 4569

Category: Informational
G. Camarillo

Ericsson

July 2006

\title{
Internet Assigned Numbers Authority (IANA) Registration of the Message Media Feature Tag
}

Status of This Memo

This memo provides information for the Internet community. It does not specify an Internet standard of any kind. Distribution of this memo is unlimited.

Copyright Notice

Copyright (C) The Internet Society (2006).

Abstract

This document registers with the IANA a new media feature tag associated with the 'message' media type. This media feature tag indicates that a particular device supports 'message' as a streaming media type. Media feature tags can be used to route calls to devices that support certain features.

Table of Contents

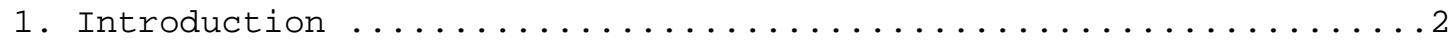

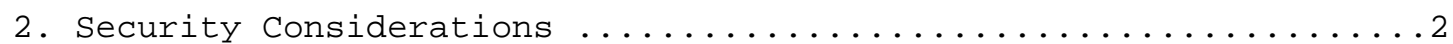

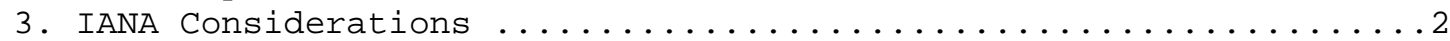

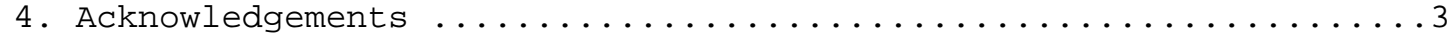

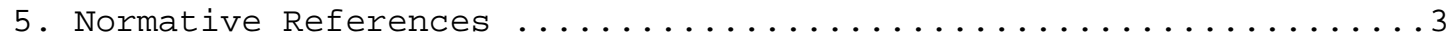




\section{Introduction}

The Session Description Protocol (SDP) specification [5] defines a number of media types. RFC 3840 [4] registers with the IANA media feature tags associated with all those media types except for the 'message' media type. This document registers a new media feature tag that is associated with the 'message' media type.

The reason why the 'message' media feature tag was not registered by RFC 3840 was that when RFC 3840 was published, the SDP specification was RFC 2327 [1]. RFC 3840 defined media feature tags for all the media types defined by RFC 2327. However, RFC 2327 did not define the 'message' media type. This media type was defined by the revised SDP specification [5], which was published after RFC 3840.

\section{Security Considerations}

Section 11.1 of RFC 3840 [4] discusses security considerations related to the use of media feature tags.

3. IANA Considerations

This specification registers a new media feature tag in the SIP [3] tree per the procedures defined in RFC 2506 [2] and RFC 3840 [4].

Media feature tag name: sip.message

ASN.1 Identifier: 21

Summary of the media feature indicated by this tag: This feature tag indicates that the device supports message as a streaming media type.

Values appropriate for use with this feature tag: Boolean.

The feature tag is intended primarily for use in the following applications, protocols, services, or negotiation mechanisms: This feature tag is most useful in a communications application for describing the capabilities of a device, such as a phone or PDA.

Examples of typical use: Routing a call to a phone that can support session-based instant messaging.

Related standards or documents: RFC 4569.

Security Considerations: Security considerations for this media feature tag are discussed in section 11.1 of RFC 3840. 


\section{Acknowledgements}

The need for this registration was discussed with Jonathan Rosenberg, Colin Perkins, and Jon Peterson.

5. Normative References

[1] Handley, M. and V. Jacobson, "SDP: Session Description Protocol", RFC 2327, April 1998.

[2] Holtman, K., Mutz, A., and T. Hardie, "Media Feature Tag Registration Procedure", BCP 31, RFC 2506, March 1999.

[3] Rosenberg, J., Schulzrinne, H., Camarillo, G., Johnston, A., Peterson, J., Sparks, R., Handley, M., and E. Schooler, "SIP: Session Initiation Protocol", RFC 3261, June 2002.

[4] Rosenberg, J., Schulzrinne, H., and P. Kyzivat, "Indicating User Agent Capabilities in the Session Initiation Protocol (SIP)", RFC 3840, August 2004 .

[5] Handley, M., Jacobson, V., and C. Perkins, "SDP: Session Description Protocol", RFC 4566, July 2006.

Author's Address

Gonzalo Camarillo

Ericsson

Hirsalantie 11

Jorvas 02420

Finland

EMail: Gonzalo.Camarillo@ericsson.com 
Full Copyright statement

Copyright (C) The Internet Society (2006).

This document is subject to the rights, licenses and restrictions contained in BCP 78, and except as set forth therein, the authors retain all their rights.

This document and the information contained herein are provided on an "AS IS" basis and THE CONTRIBUTOR, THE ORGANIZATION HE/SHE REPRESENTS OR IS SPONSORED BY (IF ANY), THE INTERNET SOCIETY AND THE INTERNET ENGINEERING TASK FORCE DISCLAIM ALL WARRANTIES, EXPRESS OR IMPLIED, INCLUDING BUT NOT LIMITED TO ANY WARRANTY THAT THE USE OF THE INFORMATION HEREIN WILL NOT INFRINGE ANY RIGHTS OR ANY IMPLIED WARRANTIES OF MERCHANTABILITY OR FITNESS FOR A PARTICULAR PURPOSE.

Intellectual Property

The IETF takes no position regarding the validity or scope of any Intellectual Property Rights or other rights that might be claimed to pertain to the implementation or use of the technology described in this document or the extent to which any license under such rights might or might not be available; nor does it represent that it has made any independent effort to identify any such rights. Information on the procedures with respect to rights in RFC documents can be found in BCP 78 and BCP 79 .

Copies of IPR disclosures made to the IETF Secretariat and any assurances of licenses to be made available, or the result of an attempt made to obtain a general license or permission for the use of such proprietary rights by implementers or users of this specification can be obtained from the IETF on-line IPR repository at http://www.ietf.org/ipr.

The IETF invites any interested party to bring to its attention any copyrights, patents or patent applications, or other proprietary rights that may cover technology that may be required to implement this standard. Please address the information to the IETF at ietf-ipreietf.org.

Acknowledgement

Funding for the RFC Editor function is provided by the IETF Administrative Support Activity (IASA). 